\title{
Homossexuais, sim, mas no feminino
}

\section{Vera Pollo}

\begin{abstract}
Resumo
O presente artigo propõe-se discorrer sobre aquelas que se dizem "homossexuais" no feminino, tomando como eixo o caso freudiano que se tornou conhecido como "A jovem homossexual". A autora relembra que foi justamente na escrita desse caso que Freud deixou clara a distinção entre posição sexual e escolha de objeto, e que Lacan, ao relê-lo, observou o quanto a homossexualidade feminina ensina sobre as etapas do encaminhamento da mulher. O texto percorre algumas passagens da biografia de Margarethe Csonka Trautenegg, a qual foi publicada com o título Desejos secretos: a história de Sidonie C., a paciente homossexual de Freud (2008). Em seguida, desenvolve com Lacan uma articulação do discurso sexual com a escolha homossexual feminina para abordar aspectos do quadro lógico da sexuação, em particular o quantificador não-toda.
\end{abstract}

\section{Palavras-chave:}

Homossexualidade feminina; Posição sexual;

Escolha de objeto; Sexuação; Não-toda.

\section{Homosexuals, indeed, but in the feminine}

\begin{abstract}
The present article proposes to discuss those that are called "homosexual" in the feminine, taking as its axis the Freudian case that became known as "The homosexual girl". The author recalls that it was precisely in the writing of this case that Freud made clear the distinction between sexual position and choice of object, and that Lacan, in reviewing it, observed how much female homosexuality teaches about the steps of the woman's referral. The text follows some passages of the biography of Margarethe Csonka Trautenegg, which was published under the title of Desejos secretos: a história de Sidonie C., a paciente homossexual de Freud (2008). He then develops with Lacan an articulation of sexual discourse with the female homosexual choice in order to address aspects of the logical framework of sexuation, in particular the non-whole quantifier.
\end{abstract}




\section{Keywords:}

Female homosexuality; Sexual position; Choice of object; Sexuation; Not all.

\section{Homosexuales, sí, pero en femenino}

\section{Resumen}

El presente artículo se propone a discurrir sobre aquellas que se dicen "homosexuales", en femenino, tomando como eje el caso freudiano que se hizo conocido como "La joven homosexual". La autora recuerda que fue justamente en la escritura de este caso que Freud dejó clara la distinción entre posición sexual y elección de objeto. Lacan, al releerlo, observó cuánto la homosexualidad femenina enseña sobre las etapas del encaminamiento de la mujer. El texto acude a algunos fragmentos de la biografía de Margarethe Csonka Trautenegg, publicada bajo el título de Desejos secretos: a história de Sidonie C., a paciente homossexual de Freud (2008). En seguida, desarrolla con Lacan una articulación del discurso sexual con la elección homosexual femenina, para abordar aspectos del cuadro lógico de la sexuación, en particular, el cuantificador no-todo.

\section{Palabras clave:}

Homosexualidad femenina; Posición sexual;

Elección de objeto; Sexuación; No-todo.

\section{Homosexuels, oui, mais au féminin}

\section{Résumé}

Le présent article propose de traiter des « homosexuelles », au féminin, en prenant pour axe le cas freudien connu sous le nom de « La jeune homosexuelle ». L'auteur rappelle que c'est précisément dans l'écriture de ce cas que Freud a précisé la distinction entre position sexuelle et choix d'objet, et que Lacan, lorsqu' il relit Freud, a observé combien l'homosexualité féminine enseigneà propos des étapes du devenir de la femme. Ce texte suit quelques passages de la biographie de Margarethe Csonka Trautenegg, qui a été publiée sous le titre de Desejos secretos: a história de Sidonie C., a paciente homossexual de Freud (2008). Il développe ensuite, avec Lacan, une articulation du discours sexuel avec le choix homosexuel féminin, pour aborder les aspects du cadre logique de la sexuation, en particulier le quantificateur pas-toute.

\section{Mots-clés:}

Homosexualité féminine; Position sexuelle;

Choix de l'objet; Sexuation; Pas-toute. 
Encontramo-nos em certo momento histórico, ou, pelo menos, em certa sociedade, que não pode dispensar a norma, o padrão de conduta, o espetáculo e a performance. Em 3 de fevereiro de 1972, na quinta lição de O seminário, livro 19: ...ou pior, Lacan (1971-1972/2012, pp. 69-70) fazia uma previsão nos seguintes termos: "para que uma coisa tenha sentido, no estado atual do pensamento, é triste dizê-lo, mas é preciso que ela se coloque como normal". E prosseguia aproximadamente assim: a homossexualidade vai entrar na redoma do normal, a tal ponto que teremos em psicanálise novos sujeitos que virão nos dizer: "estou procurando você porque não tenho sido normalmente homossexual". Lacan esclarece que foi a partir de um substantivo grego raríssimo que se inventou a palavra norma, inexistente no discurso antigo.

Descontando-se o caráter jocoso dessa afirmação, posto que também é séria, diremos que emergem na fala dos sujeitos que recorrem explicitamente ao significante "homo", para designar sua escolha de parceiro sexual, as mesmas questões que se apresentam nas falas daqueles que se dizem "hétero". Questões que assim se formulam: Como fazer do amor uma suplência duradoura que corrija a desarmonia sexual? É possível ser ao mesmo tempo dividido e fiel? E como viver a castração sem confundi-la com a morte?

Não creio ser obra do acaso que Freud (1920/2012) tenha esclarecido a distinção entre a posição sexual de um sujeito e sua escolha de objeto/parceiro sexual justamente no caso daquela que entrou para a história da psicanálise sob a alcunha de "A jovem homossexual". Desde então afirmamos que, de acordo com o equilíbrio da balança das identificações do eu, a posição será dita "masculina" ou "feminina", ao passo que a escolha, em contrapartida, será dita "homo" ou "hétero". $\mathrm{Na}$ verdade, fenomenologicamente, isso significa apenas que alguém que é dita "mulher", ou melhor, que recebe a letra F junto à palavra "sexo" no registro civil de cunho eminentemente biológico, e que se sente subjetivamente uma mulher, tanto pode escolher como parceiro sexual um homem quanto uma mulher; e o mesmo pode ocorrer com cada um dos homens. Mulher e homem são, antes de mais nada, dois significantes, por isso suas variações semânticas serão bem maiores que as gramaticais. Mas isso não quer dizer que o sexo não seja real, e também dual, queiram-no ou não os que defendem a pluralização crescente de gêneros.

É certo que o texto freudiano preparou o terreno sobre o qual Lacan concluiu a construção de seu quadro lógico da sexuação (Figura 1) em uma das lições de $O$ seminário, livro 20: mais ainda (1972-1973/2008). Neste, o quantificador não-toda inaugura a lógica do real, pois, embora não se possa medir quantitativamente o gozo, podem-se enumerar suas irrupções. 
Figura 1. Quadro lógico da sexuação.

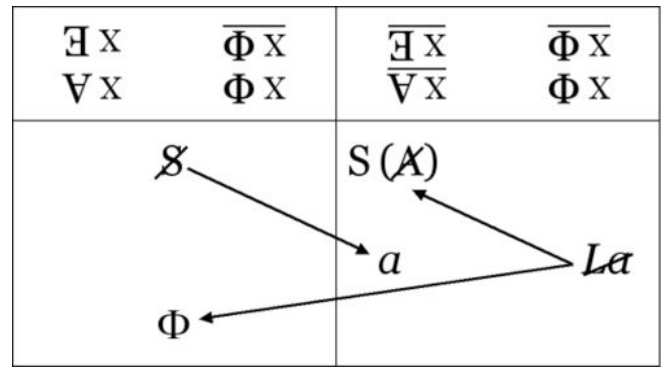

Fonte: Lacan, 1972-1973/2008, p. 84.

Freud escreve que a precocidade sexual de Herbert Graf (o Pequeno Hans) se fazia acompanhar pari passu da precocidade intelectual, eram inseparáveis. Observa também que o recalque não suprime a bissexualidade, opera apenas o "esquecimento" de uma de suas correntes, passível de ser reativada a qualquer momento; e, ainda, que o tabu do órgão genital feminino pode estender-se ao corpo da mulher como um todo. Em uma só palavra, subscrevemos a observação de Lacan de que a subversão freudiana está menos na afirmação de que a sexualidade é infantil do que em dizê-la intelectual. A sexualidade é intelectual, ou seja, a posição sexuada, assim como o inconsciente, depende da linguagem, e isso restringe suas manifestações naqueles que nada mais são do que seres falantes, ou melhor, falas-a-serem.

Desde que Ines Rieder e Diana Voigt publicaram, em 2000, a biografia intitulada Desejos secretos, ficamos sabendo que a Jovem homossexual de Freud, cujo verdadeiro nome era Margarethe Csonka-Trautenegg, ${ }^{1}$ viveu até os 100 anos de idade. Ao que tudo indica, apaixonou-se por alguns homens e muitas mulheres, mostrando-se inibida em sua vida sexual e nas demonstrações de afeto. Com as mulheres diante das quais assumia a posição de erastès, Sidonie, autodenominação que propôs às biógrafas, viajava e divertia-se, mas também sofria a inevitável desilusão do amor, que não passa pela castração.

Antes de completar 30 anos, já fizera três tentativas fracassadas de suicídio, a terceira delas como forma de evitar um casamento para o qual já estava tudo encomendado, do vestido de noiva à viagem de lua de mel. Sem coragem de promover o desejado rompimento, deu um tiro em seu próprio peito. No entanto, um cartucho com invólucro inteiriço foi retirado de seu pulmão onde se alojara, e ela sobreviveu. Às biógrafas, acabou contando que desejou casar com outro homem, o qual faleceu bem jovem de doença venérea.

\footnotetext{
1 Esse não é, todavia, o nome que aparece na capa do livro Desejos secretos, assim como no decorrer dos capítulos, em que se pode ler o nome de Sidonie Csillag, conforme Margarethe havia combinado com as autoras ao perceber que o livro sairia antes de sua morte, o que, de fato, ocorreu. Porém, foram quase simultâneos, uma vez que ela faleceu em abril de 1999, aos 100 anos de idade, e o livro foi publicado em 2000. A tradução brasileira é de 2008.
} 
Aproximando-se seu aniversário de 30 anos, Sidonie viaja a Praga e tem a oportunidade de participar do que era então chamado “jogos de senhoras”, práticas homossexuais entre amigas, que tanto podiam ser solteiras quanto casadas. Refere certo sentimento de estranheza na ocasião de um desses jogos e decide aceitar a proposta de casamento de Eduard von Weitenegg, da qual não fez parte a palavra "amor". Para ele, um casamento de negócios; para ela, um reconhecimento na "melhor" sociedade. Um casamento predestinado a um rápido fim, pois o marido a abandonaria durante a perseguição nazista aos judeus vienenses. Diferentemente dele, ela tinha ascendência judia.

Às biógrafas, Sidonie comentou que Freud lhe teria dito: "a senhora tem olhos tão astuciosos. Não gostaria de encontrá-la nesta vida como inimigo". A certa altura de sua vida, deixou despertar o desejo de pintar as mulheres de que gostava. E uma de suas melhores pinturas é justamente a daquela com quem teve, em suas próprias palavras, "uma relação sem desfecho". Embora reprovasse o discurso do capitalismo, pois dizia desprezar o trabalho assalariado e o fato de se "estar a serviço de alguém", viu-se obrigada a trabalhar para ganhar dinheiro, escolhendo alternadamente o emprego de babá, governanta e professora de línguas.

É provável que Sidonie tenha se considerado vítima do destino, pois relatou que, se algo começava a dar certo, logo em seguida estava acabado. Não chegou às vias de fato com Leonie, a dama que cortejou em sua adolescência, tampouco com Fritz, que morreu antes que algo tivesse acontecido. Estabeleceu a beleza como critério afrodisíaco, deixou-se mover pelo desejo ardente, mas considerou que satisfação e realidade não passam de aniquilação humilhante.

Freud listou pelo menos três determinantes de uma escolha homossexual de objeto-mulher na vida adulta:

a reprodução da relação mãe-bebê;

a regressão ao complexo de masculinidade da menina, isto é, o despertar da fantasia inconsciente de ter ou vir a ter pênis;

a "renúncia em benefício de", quando a menina adolescente renuncia ao amor dos homens em benefício de uma mãe ainda jovem e atraente.

Pareceu-lhe que, no caso de Sidonie/Margarethe, "a renúncia em benefício de" era evidente. Ao reler esse caso freudiano, cotejando-o com o caso Dora, Lacan (1956-1957/1998, p. 96) observou que "a homossexualidade feminina foi dotada, em toda [a] análise, de um valor particularmente exemplar, pelo que ela pôde revelar das etapas do encaminhamento da mulher, bem como sobre as interrupções que podem marcar seu destino".

Perguntamo-nos, então, o que teria levado Lacan, alguns anos mais tarde, precisamente no decorrer de seu O seminário, livro 19: ...ou pior (1971-1972/2012), a declarar que as homossexuais, no feminino, sustentam o discurso sexual com toda segurança. Largamente distantes dos sujeitos que se dizem transexuais, que pretendem corrigir o discurso sexual, se as homossexuais o sustentam, é porque também sustentam o "erro comum" que confunde o significante com o significado, o gozo 
com o falo e, por que não dizer, o falo com o pênis. Confundem, assim, o que se ouve com o que se lê. Mas Lacan não para aí, declara que as homossexuais, no feminino, participam do gozo fálico, mas ficam cegas diante do gozo feminino. Como assim? Ele prossegue dizendo que elas se movem à vontade no discurso do amor que faz suplência à relação que inexiste, pois, se existisse, seria a escrita no inconsciente de dois sexos. Consequentemente, a possibilidade da relação homem-mulher.

É realmente curioso, mas talvez não chegue a ser paradoxal, que as homossexuais, cuja procura pelo tratamento analítico é hoje bem significativa, estejam soletrando aos psicanalistas as letras de um gozo do qual elas mesmas não desfrutam. Pois é verdade que, desde que Lacan propôs suas Diretrizes para um congresso sobre a sexualidade feminina, ainda em 1958, ele subscreveu a observação de Jones segundo a qual haveria a presença do "homem invisível" na vida sexual das homossexuais, e a ele estaria endereçado o cuidado da homossexual com o gozo da parceira.

Nesse ponto, podemos lembrar novamente o caso de Sidonie/Margarethe, que fazia a corte a Leonie, a dama de má reputação, não às escondidas, não em qualquer lugar, mas exatamente na rua do escritório de seu pai. E o que ela obteve? No dia em que se cruzaram, encontrou apenas o olhar acusatório desse pai e o silêncio de sua voz. Nos termos de Lacan, naquele momento de seu ensino, o pai potencialmente simbólico regredira, no inconsciente do sujeito, ao pai imaginário. Em 1971, logo na primeira lição do Seminário ...ou pior, Lacan articula a escolha homossexual feminina ao Ecce homo do amor.

Ecce homo - Eis o homem! - , as palavras com que Pilatos entregou Jesus aos tiranos, são também o tema do livro mais polêmico de Nietzsche, que o compara a Zaratrusta. E são, ainda, o tema de muitos quadros célebres, entre os quais se destaca Ecce homo, de Caravaggio (Figura 2), também conhecido como $O$ senhor da vara verde.

Figura 2. Ecce homo, de Caravaggio.

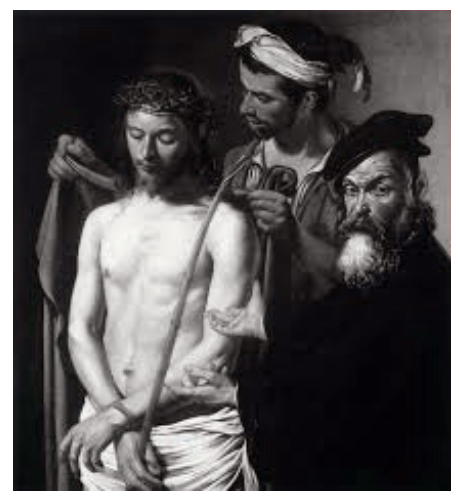

Fonte: Recuperado de http://www.caravaggio.org/ecce-homo.jsp 
Trabalhando com a distinção entre função, argumento e variável, Lacan nos dá a entender, primeiramente, que uma função pode incluir um lugar vazio em que se inscreverá um argumento. Assim, por exemplo, na função fálica, pode-se inscrever o argumento "dizer sim”, ou seu contrário, “dizer não”, mas é somente a partir da relação do argumento com a variável, que o conduz à existência, que o subjetiva e singulariza, se assim preferirmos, que dependerá o valor de verdade ou de falsidade do argumento.

Podemos dizer que a função fálica, que é função de linguagem, visa a "preencher a hiância da não existência de A relação sexual”, e assim obtura a relação. Pois, uma vez que ela é possível para todos, como sujeitos, não lhe é possível compor dois grupos nitidamente separados, passíveis de formarem, mediante correspondência biunívoca, dois universos de linguagem.

O real animal, seu modelo de acasalamento, observa Lacan, pode sugerir a fantasia anímica do encontro de duas almas, "nascidas uma para a outra". Modelo que até pode sustentar-se em uma fala de amor, mas não no ato em que o gozo do corpo de um não faz signo para o outro. Falar em "homem invisível" é também falar em Ecce homo e, prosseguindo a série, em pai da horda. É lógica a necessidade da existência de um "dizer que não" à castração, pois o gozo, sem as bordas que somente o objeto $a$ pode lhe dar, se estenderia indefinidamente ao infinito. Arriscar-se-ia tornar-se letal. Escolher uma mulher leva à necessidade lógica do Um da exceção, ao necessário desse Um, que se sustenta além da função fálica. Totem e tabu não é apenas a escrita de um mito até então inexistente, é a escrita do Pai real. E não se trata de acontecimento, diz Lacan, mas de estrutura, pois, a partir do mito, pode-se falar de todo homem, outra forma de dizer que só há uma libido e que ela é sempre masculina.

Por um lado, fala-se de amor, e falando se faz amor. Faz-se mito ou poesia. Mas a castração é real. O real biológico ajuda a entendê-la: há dois tipos de gametas em cuja junção não ocorre a fusão imediata dos dois em um, mas a meiose, "uma tremenda evacuação". Quando se trata de sexo, trata-se de sexo oposto, mas não é verdade que o feminino seja simplesmente o oposto do masculino. Aquele que extrai seu ser da fala não tem com o sexo uma relação quantificável, por isso não tem parceiro específico.

O quantificador não-toda resolve a indecisão lógica que se impõe toda vez que é exigida a dupla negação, que não é nem a afirmação simples nem a negação simples. É o que ocorre, por exemplo, na relação das mulheres com a castração. Se não se pode dizer "nenhuma mulher é castrada", em que a negação recai sobre o sujeito, tampouco se pode dizer "nenhuma mulher não é castrada", em que a negação recai também sobre o verbo. Por isso, ao substituirmos a função castração pela função fálica, como faz Lacan, seremos levados a dizer com ele que: “(...) a mulher tem, em algum lugar, relação com a função fálica, e nada mais” (Lacan, 1971-1972/2012, p. 44). Não se pode precisar onde se deu sua relação com o falo, sabe-se apenas que ela existe porque se deixa ver, mostra-se. 
$\mathrm{O}$ ato sexual encontra suas coordenadas na cena da fantasia, em que o sujeito se deixa determinar por uma das formas do objeto $a$ : seio, fezes, olhar ou voz, mas o gozo, não de A mulher, porém de uma, se bifurca entre a falta do Outro - em $S(\mathbb{A})$ - e o $\varphi$, significado dessa hiância - fenda enorme, boca esfomeada - no campo da significância e no real.

\section{Referências bibliográficas}

Freud, S. (1909/2012). Análise de uma fobia em um menino de cinco anos. (José Luis Etcheverry, Trad.). In J. Strachey (Ed.). Obras completas (Vol. 10, 2a. ed., pp. 1-118). Buenos Aires: Amorrortu.

Freud, S. (1920/2012). Psicogênese de um caso de homossexualidade em uma mulher. (José Luis Etcheverry, Trad.). In J. Strachey (Ed.). Obras completas (Vol. 18, 2a. ed., pp. 137-164). Buenos Aires: Amorrortu.

Lacan, J. (1956-1957/1998). O seminário, livro 4: a relação de objeto. (Dulce Duque Estrada, Trad.). Rio de Janeiro: Jorge Zahar.

Lacan, J. (1958/1998). Diretrizes para um congresso sobre sexualidade feminina.

In J. Lacan. Escritos (pp. 734-758). (Vera Ribeiro, Trad.). Rio de Janeiro: Jorge Zahar.

Lacan, J. (1971-1972/2012). O seminário, livro 19: ...ou pior. (Vera Ribeiro, Trad.). Rio de Janeiro: Jorge Zahar.

Lacan, J. (1972-1973/2008). O seminário, livro 20: mais, ainda. (M. D. Magno, Trad.). Rio de Janeiro: Jorge Zahar.

Rieder, I. \& Voigt, D. (2008). Desejos secretos: a história de Sidonie C., a paciente homossexual de Freud. São Paulo: Companhia das Letras.

Recebido: 14/10/2017

Aprovado: 09/01/2018 